\title{
Allowance removal from green pieces as a method for improvement surface quality of advanced ceramics
}

\author{
L.E.A. Sanchez ${ }^{a,}{ }^{*}$, G. Bukvic ${ }^{b}$, A.A. Fiocchi ${ }^{c}$, C.A. Fortulan ${ }^{\mathrm{d}}$ \\ a Sao Paulo State University - Unesp, Department of Mechanical Engineering, Bauru, SP, 17033-360, Brazil \\ ${ }^{\mathrm{b}}$ University of the Sacred Heart - USC, Bauru, SP, 17011-160, Brazil \\ ${ }^{\mathrm{c}}$ Federal University of Uberlandia - UFU, Department of Mechanical Engineering, Uberlandia, MG, 38408-100, Brazil \\ d University of Sao Paulo - USP, Department of Mechanical Engineering, Sao Carlos, SP, 13566-590, Brazil
}

\section{A R T I C L E I N F O}

\section{Article history:}

Available online 8 March 2018

\section{Keywords:}

Green machining

Density gradient

Distortion

Surface finishing

Single-action uniaxial pressing

\begin{abstract}
A B S T R A C T
Advanced ceramics are usually machined after sintering in order to produce details and/or achieve the dimensional and geometric tolerances specified by project. However, this operation is neither cheap nor easy since it requires diamond tools, machine tools of high stiffness, and very low removal rates, even so, the finished parts might invariably contain critical defects. Machining of compacted ceramic powder before sintering, named green machining, is an alternative. This method does not require cutting fluid, presents great machinability, low energy consumption and few or no introduction of damages in the sintered workpiece. The single-action uniaxial pressing is the most used method for obtaining green ceramic pieces. Nevertheless it produces significant density variations in the outer regions of the piece, mainly located around the top and bottom edges, while the variation inside is smaller. The nonuniformity of density is considered responsible for distortion of the ceramic part during sintering. In this study, the distortion of the sintered workpieces was evaluated after green ceramic workpieces were machined using five different allowance values $(1,2,3,4$, and $5 \mathrm{~mm})$ in order to progressively remove the greatest density gradients. The distortion analysis was made on the top and bottom regions of the workpiece, where each upper and lower punch.

operates, respectively. It was found that the distortion of the top region of the sintered workpieces was reduced about $97 \%$ when there was $5 \mathrm{~mm}$ of allowance removal and $82 \%$ for $1 \mathrm{~mm}$ of allowance. In the bottom region, the reduction was about $91 \%$ for removal of $5 \mathrm{~mm}$ of allowance and $48 \%$ for $1 \mathrm{~mm}$. Cutting tool wear, cutting force, and surface roughness of green and sintered workpieces were also analyzed. In general, the influence of tool wear on surface roughness of sintered pieces and the correlation between surface roughness of the sintered pieces and the corresponding green ones were observed.
\end{abstract}

(C) 2018 Elsevier Ltd. All rights reserved.

\section{Introduction}

Although advanced ceramics have several favorable properties, such as high resistance to wear and temperature, chemical stability, and low density, these materials also have characteristics that limit their applications, especially regarding low fracture toughness, responsible for low impact resistance and reduced plastic deformation.

Machining using diamond tool is the main technique to achieve specified dimensions and surface finishing of ceramic parts. Depending on the workpiece size, material, shape, and surface

\footnotetext{
* Corresponding author.

E-mail address: sanchez@feb.unesp.br (L.E.A. Sanchez).
}

quality, the machining of the sintered ceramic can amount to more than $50 \%$ of the production costs (Strakna et al., 1996). Among the machining processes, grinding represents more than $80 \%$ of all advanced ceramic machining. However, due to high degree of brittleness, mechanical components invariably suffer surface/subsurface damages such as cracks during conventional material removal processes, compromising mechanical strength (Marinescu et al., 2007). Furthermore, hard ceramic machining demands for high stiffness machine-tools as well as diamond cutting tools, becoming the material removal process expensive.

According to experimental results from Xu and Jahanmir (1995) associated with study by Swain (1979), in machining of sintered polycrystalline ceramic different types of damages are verified as consequence of three different material removal mechanisms: (1) 
intergranular fracture and dislodgment of grains; (2) microcracks and formation of grain fragments through intragranular cracks; (3) and removal of large portions of grains by chipping due to the propagation of nanogranular cracks. Depending on highly controlled machining conditions, brittle removal mechanisms that involve the formation of cracks can be minimized, or even ductile machining can be achieved, in which removal mechanisms are characterized by plastic deformation, like in metals (Zhong, 2003; Ajjarupu et al., 2004). The two material removal modes, ductile or brittle, are associated with a critical depth of cut, which if exceeded, may result in damages. In order to reduce them, some works (Marshall et al., 1983; Malkin and Ritter, 1989; Blackley and Scattergood, 1991, 1994) recommend the use of much lower material removal rates than those used in finishing of metal components. Nevertheless, this procedure does not guarantee that ceramic components will be microcrack-free.

In order to improve the machinability and minimize ceramic material damages, some non-conventional machining processes have been studied. Electrodischarge machining process (EDM) is one of them, since it can produce variable shapes and it is not dependent on the hardness or abrasiveness of the material itself. However, the ceramic electrical conductivity must be higher than $0.01 \mathrm{~cm}^{-1}$ such as boron carbide $\left(\mathrm{B}_{4} \mathrm{C}\right)$ and silicon infiltred silicon carbide ( $\mathrm{SiSiC}$ ), which were machined successfully by Sánchez et al. (2001). The fact of the most of the ceramics, for instance $\mathrm{Al}_{2} \mathrm{O}_{3}$, $\mathrm{ZrO}_{2}, \mathrm{Si}_{3} \mathrm{~N}_{4}$ and $\mathrm{SiC}$, are electrically nonconductive can be minimized adding some doping to improve their conductivity, so that them become susceptible to the EDM. This is the case of studies carried out by Lee and Lau (1991), wherein up to $40 \%$ of TiC was included in an $\mathrm{Al}_{2} \mathrm{O}_{3}$ to improve its conductivity. Another wellestablished technique, since Mohri et al. (1996), is based on application of a metallic layer of high conductivity on the workpiece surface. But, in relation to the workpiece surface integrity of ceramic machined by EDM, Sánchez et al. (2001) state that surface and subsurface damages may be induced due to the thermal fatigue or to the material recast on the surface after removal.

Among the non-conventional machining processes, laser assisted machining (LAM) possibly is the most promising technique applied on the removal of difficult-to-machine materials. In this technique, the material is locally heated by an intense laser source prior to material removal, without melting or sublimation of the ceramic (Samant and Dahotre, 2009). As a result of the material heating, its yield strength decreases promoting lower both machining forces and cutting tool wear, besides improving the surface finishing (Chang and Kuo, 2007). Previously to the laser use, the plasma was the heating source used for softening the material, which it achieved success in many metallic materials, such as Inconel 718 in study conducted by López de Lacalle et al. (2004), but the plasma was not effective in ceramic materials according to Kitagawa and Maekawa (1990).

An alternative to avoid the damages in ceramic machining is the use of green machining technique, which removes material from compacted pieces before their sintering (i.e. in the green state). This process consumes few cutting energy, at least 50 times lower than in steel cutting for a same removed material volume, and is cheaper than removing material of a sintered ceramic, since green ceramic presents good machinability (Su et al., 2008; Ekabaram, 2008).

Green machining is carried out without cutting fluid, being this fact highly beneficial since if it is used makes the workpiece manufacturing more expensive, causing environmental problems and health risks. Even so, according to Debnath et al. (2014), approximately $85 \%$ of the cutting fluids used around the world are mineral-based cutting fluids. The cutting fluids require systems for storage, treatment, and recycling when they are discarded. Previous studies, such as Wichmann et al. (2013) and Zhao et al. (2012), have demonstrated that the highest consumption of tap water in machining processes is related with the use of cutting fluids, mainly for cleaning machined workpieces. Cutting fluids also contain biocidal compounds to prevent the growth of fungi and bacteria. However, these compounds are harmful to the health of operators because they release formaldehydes. Operators exposed to cutting fluid and its fumes may develop allergic dermatitis and respiratory diseases as reported by Burton et al. (2012). A study presented by Trafny (2013) revealed the presence of biofilms in cutting fluids, formed by fungi and nontuberculous mycobacteria that cause hypersensitivity pneumonitis and are not eliminated by conventional biocides, and that, moreover, may be stored in the system's metal components. Minimum quantity lubrication (MQL) technology is presented as an alternative to reduce fluid consumption in machining. MQL consists in spraying micro-oil particles to be used as cutting fluid. The flow rate used with this technique is established between $10 \mathrm{ml} / \mathrm{h}$ and $100 \mathrm{ml} / \mathrm{h}$. Using several types of vegetable oils, Pereira et al. (2017) found satisfactory results in milling of Inconel 718 applying high sun flower oil. According to authors, the use of biodegradable/vegetable oils is required to achieve a full environmental process optimization. Besides, the use of biodegradable/vegetable oils prevents not only environmental issues but also health diseases. However, the MQL technique cannot be used in green machining since the workpiece is impregnate by lubricant, which it is capable to modify the sintering mechanisms and preclude the powder recycling, besides that the spraying causes workpiece erosion and spreads the powder.

Goindi and Sarkar (2017) state that researchers have tried to machine components without using any cutting fluids. Machining carried out without the assistance of cutting fluids is also termed as "dry machining", which green machining also makes part of it. Gouveia et al. (2017) studied green machining in dental prostheses composed by zirconia stabilized with $3 \mathrm{~mol} \%$ of yttria (3Y-TSZ), whose wasted powder was recycled. As result, they concluded that the wasted powder after treatment can be used in other applications, mainly in jewelry, without loss of mechanical resistance in relation to the original powder. In this case, the use of any fluid would become the machining process impracticable.

According to Klock et al. (2001), the primary objective of the machining sequence, prior to ceramic sintering, is usually to produce a contour similar to the finished component and a surface rim zone free from damage. In this way, complex shapes and details can be manufactured. In industrial practice, machining of green oxide ceramics with a defined cutting edge tool is an efficient shaping method as a step process of ceramic production. Nevertheless, as green machining was mostly considered a subordinate step on the way towards the ceramic component, there was a considerable deficit in fundamental process knowledge in the past (Klock et al., 2001).

Maier and Michaeli (1997) machined green ceramic workpieces (99.7\% pure alumina) and observed a positive relationship between surface quality and mechanical strength after sintering. In both states, green or sintered, the machining under severe conditions is accompanied by chippings and invariably brings on microcracks on the surface of the piece, whereas mild machining conditions are capable of producing damage free pieces and surfaces with visible marks only left by cutting tool tip. These two mechanisms were called "chipping mode" and "cutting mode", respectively. The authors found that green workpieces have very similar mechanical strength regardless of their surface finishing. However, the surface finishing produced by each one of these two modes affects the bending strength of sintered workpieces. As a result, the machined green ceramics with the best surface finishing presented greater mechanical strength (around 8\%) when compared to the non- 
machined sintered ones. On the other hand, the green workpieces with the poorest surface finishing produced the lower mechanical strength (approximately 10\%).

Many of the problems involving green machining of ceramics include low mechanical strength of the green pieces that may not resist to machining force as well as clamping stress (Desfontaines et al., 2005). Regarding to machining force, the values tend to increase as the cutting tool wear, especially if it is made of high speed steel (HSS), or even made of cemented carbide when used in some types of more abrasives ceramics. Ng et al. (2006) state that flank wear greater than $0.1 \mathrm{~mm}$ can already cause damages to the workpiece surface due to excessive specific cutting pressure, but in literature on green machining there are no studies that relate the cutting tool wear with surface roughness or even force with surface roughness.

Uniaxial pressing is one of the most used techniques for obtaining green ceramic pieces due to low cost and simplicity, preferably in pieces with a small number of different sections. However, the powder pressing causes intense friction among adjacent particles, and even more intense between the particles and the die wall. Consequently, there is a non-uniform filling of powder inside the die resulting in a piece with different density gradients (Albaro, 2000; Bencoe et al., 2008). The non-uniformities of density distribution may persist through the subsequent stages of the manufacturing process, the sintering in each corresponding region of the piece suffers different intensities of volume reduction with different shrinkage values that can lead to distortions, residual stresses, and even cracking of the sintered ceramic (Wu et al., 2005). Fig. 1 schematically illustrates the relative density distribution of a green piece uniaxially prensed by single-action, as obtained by simulation (Fig. 1a) as experimentally (Fig. 1b).

It can be seen that the powder around the bottom edge is much less compressed than the powder near the top edge. This means that the regions of high gradients near the outer cylinder surface should be removed to leave the remained compacted piece with more uniform densities. Zipse (1997) removed $2 \mathrm{~mm}$ from a cylindrical compact of $20 \mathrm{~mm}$ radius made of $\mathrm{Al}_{2} \mathrm{O}_{3}$ and $\mathrm{ZrO}_{2}$, by turning. The part sintered non-machining suffered a distortion of $0.7 \mathrm{~mm}$ while the machined part and subsequently sintered had a distortion around $0.1 \mathrm{~mm}$. However, other allowances amounts were not studied as well as information relative to machining parameters, such as machining force, cutting tool material, and cutting tool wear, were not provided. In similar study, Bukvic et al. (2012) reached a reduction of $57 \%$ in distortion of $\mathrm{Al}_{2} \mathrm{O}_{3}$ compact but the removed allowances amounts were limited only up to $1 \mathrm{~mm}$. Ng et al. (2006) in their work on green machining discussed the binder type influence on the machinability but not the distortion in sintered pieces.

The green machining can play an important role in the near net shape technique in order to obtain sintered ceramics with low distortion and good surface finishing to bring them closer to their

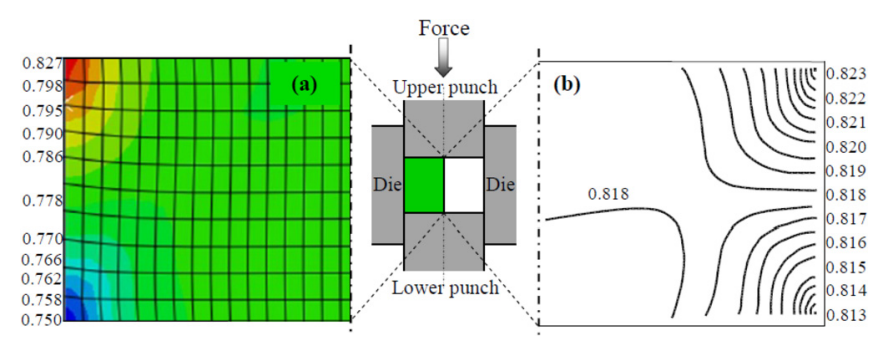

Fig. 1. Relative density distribution at the end compression obtained (a) experimentally and (b) by simulation (adapted from Frenning, 2007; Diarra et al., 2012). final dimensions. The success of these assumptions would allow an important advancement toward to the reduction of allowance reserved to the finishing machining of sintered pieces with consequent reduction of cost, manufacturing time, and minimization of damages, which is the principle of the near net shape technique (Klock et al., 2001).

In relation to the green machining focused to the near net shape, it is worth observing that the practice of removing a constant allowance value can produce distortions on sintered ceramic, since there are two regions of densities much different and the complete removing of non-uniformities density is only possible if $50 \%$ of the radial value of the green piece is taken off. The evaluation of the distortion for progressive allowance removal values is required. Moreover, the surface roughness is part of the ceramic component final specifications and thereby this output variable must be also included in the near net shape technique. Both cutting force associated to cutting tool wear and machining parameters impact on surface finishing of green pieces and, as consequence, they must reflect on sintered pieces. All these aspects are not much studied, especially the lack of investigations on geometric deviation, particularly distortion, and strategies for its minimization using green allowance removal.

The present work deals with the effect of progressive allowance removals of green machined alumina workpieces by turning on their distortion after sintering. Single-action uniaxial pressing was chosen to produce cylindrical workpieces. This pressing technique produces a compact ceramic having different density gradients at its top and bottom volumes, where the highest and lowest density gradients are situated, respectively. The green ceramic material was removed at constant depth of cut on the workpiece's generatrix. Five different allowance values were used removing up to $40 \%$ of the total radius of workpieces with $25 \mathrm{~mm}$ diameter. Such allowance removal value is the largest utilized in works on the subject. In addition, the cutting tool wear and its influence on the surface roughness of the green workpieces and especially on the surface finishing from the correspondent sintered part were evaluated. The progressive allowance removal, the distortion of the workpieces taking into account the top and bottom portions, the influence of the green workpiece surface finishing on the sintered ones, and the machinability gather new aspects in literature which can contribute in manufacturing optimization of ceramic components in order to reduce costs and energy consumption.

\section{Experimental procedure}

Cylindrical specimens with dimensions of $\varnothing 25.0 \times 39.0 \mathrm{~mm}$ were compacted by single-action uniaxial pressing using alumina powder at pressure of $120 \mathrm{MPa}$. The ratio of diameter to length of the compact was about $1: 1.5$. This value was chosen by the fact of highlighting the density variation of the specimens, according to Richerson (1992) and German (1994), which becomes adequate to the purpose proposed in this study.

The alumina mixture with agglomerates was made in a ball mill with cylindrical elements in zirconium $(\varnothing 12.0 \mathrm{~mm} \times 12.0 \mathrm{~mm})$. A suspension with $30 \%$ in powder alumina volume was dispersed in a $68 \%$ volume of distilled and deionized water and $1 \%$ volume of PVAL was added, and the rest, $1 \%$ volume of ammonium polyacrylate (Dispersal 130). As recommended by Leriche et al. (1988) deflocculant associated with the mechanical mixture was used to guarantee a more efficient homogenization of the mixture. The ceramic powder was obtained using the spray-drier technique. 99.9\% pure alumina was used, and its characteristic shape is shown in Fig. 2, which was obtained by scanning electron microscopy (SEM).

Table 1 presents the ceramic composition used: Calcined Alumina A1000-SG, (Almatis, Inc.) with particles of $0.4 \mu \mathrm{m}$ in 


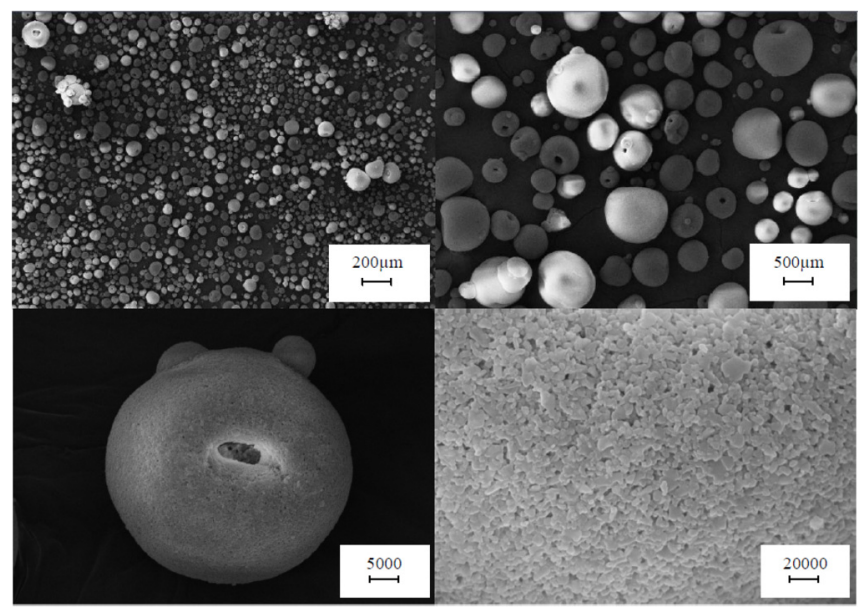

Fig. 2. High magnification of dust produced using the spray drier method: (a) $100 \times$; (b) 500X; (c) 5000X; and (d) 20000X.

Table 1

Chemical composition (wt.\%) of the Alumina A1000-SG, (Almatis, Inc.).

\begin{tabular}{lllllll}
\hline $\mathrm{Al}_{2} \mathrm{O}_{3}$ & $\mathrm{SiO}_{2}$ & $\mathrm{Fe}_{2} \mathrm{O}_{3}$ & $\mathrm{Na}_{2} \mathrm{O}$ & $\mathrm{CaO}$ & $\mathrm{B}_{2} \mathrm{O}_{3}$ & $\mathrm{MgO}$ \\
\hline 99.9 & 0.03 & 0.02 & 0.07 & 0.02 & 0.001 & 0.04 \\
\hline
\end{tabular}

equivalent average diameter, surface area of $7.7 \mathrm{~m}^{2} / \mathrm{g}$ and real density $\left(\rho_{\text {real }}\right)$ of $3.99 \mathrm{~g} / \mathrm{cm}^{3}$.

The green ceramic specimens were machined in a milling machine. However, the operation carried out was turning with the compact fixed to the vertical spindle, which provides the rotation movement, and the toolholder was fixed to a sturdy device attached to the machine table which executes the vertical feed movement on the compact, and the horizontal movement that produces radial action for depth of cut. The option for employing a milling machine is due to its high stiffness, easily access around the workpiece with room for fixing the device and instruments. Besides, the table of the milling machine has low speed which allows short feeds, even shorter than in a conventional lathe.

The device fixed to the machine table was especially designed for this study, which allows fixing a toolholder attached to a load

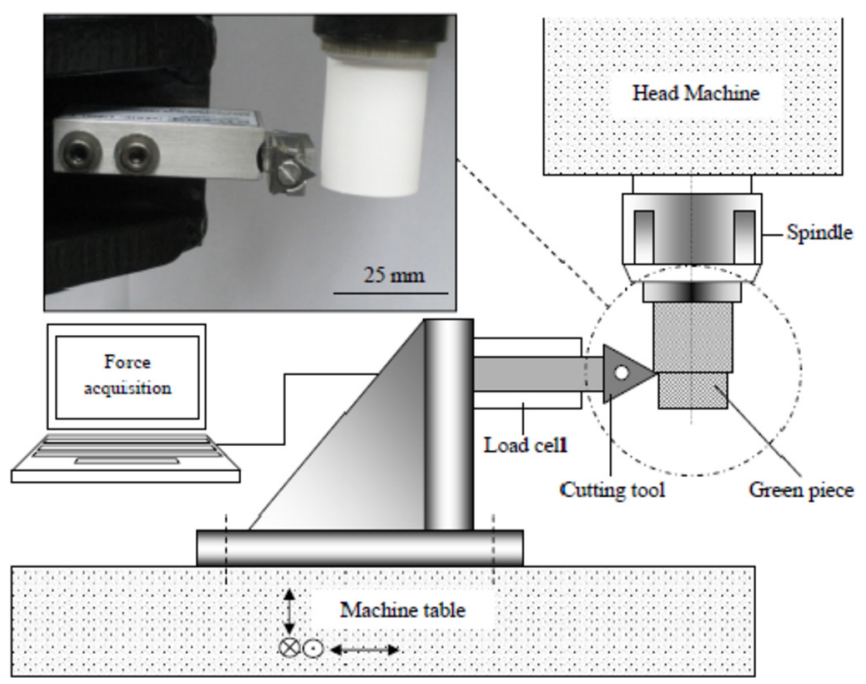

Fig. 3. Schematic drawing of the experimental setup. cell, manufactured by R\&S (model MB), with nominal scale of $20 \mathrm{~N}$, as shown in Fig. 3. The force acquisition frequency was 100 points/ min using the software LabView 6.1.

Uncoated cemented carbide cutting tools with no chip breakers, class $\mathrm{K} 10$, and $0.05 \mathrm{~mm}$ tip radius were used. The criterion established at the end of life was the maximum flank wear (VBmax $) \geq 0.4 \mathrm{~mm}$, according to ISO Standard 3685 .

Five allowance values were removed from green compacts: 1.0 , 2.0, 3.0, 4.0, and $5.0 \mathrm{~mm}$. A brand new insert was used for each allowance removal value. Each one of these allowances was removed with several passes using $1.0 \mathrm{~mm}$ of depth of cut $\left(a_{p}\right)$, cutting speed $\left(\mathrm{V}_{\mathrm{c}}\right)$ of $78.5 \mathrm{~m} / \mathrm{min}$, and feed rate (f) of $22.4 \mathrm{~mm} / \mathrm{min}$. These input parameter values were chosen from a range of previously tested values. All other machining conditions tested produced excessive damages on the workpiece surface, especially dislodgement of ceramic agglomerates. Fig. 4 shows eight examples of machined surfaces under different $\mathrm{f}$ and $\mathrm{V}_{\mathrm{c}}$, which were observed and the option with the best surface finishing was chosen (Fig. 4c).

Surface images were obtained from an optical microscope (model SMZ800, Nikon) coupled with a digital camera. The same equipment was also used to measure the cutting tool wear.

The input parameters and output variables in the experiment are summarized in Fig. 5.

Due to low mechanical strength, the green workpieces were carefully glued to a custom made steel base with a cylindrical cavity

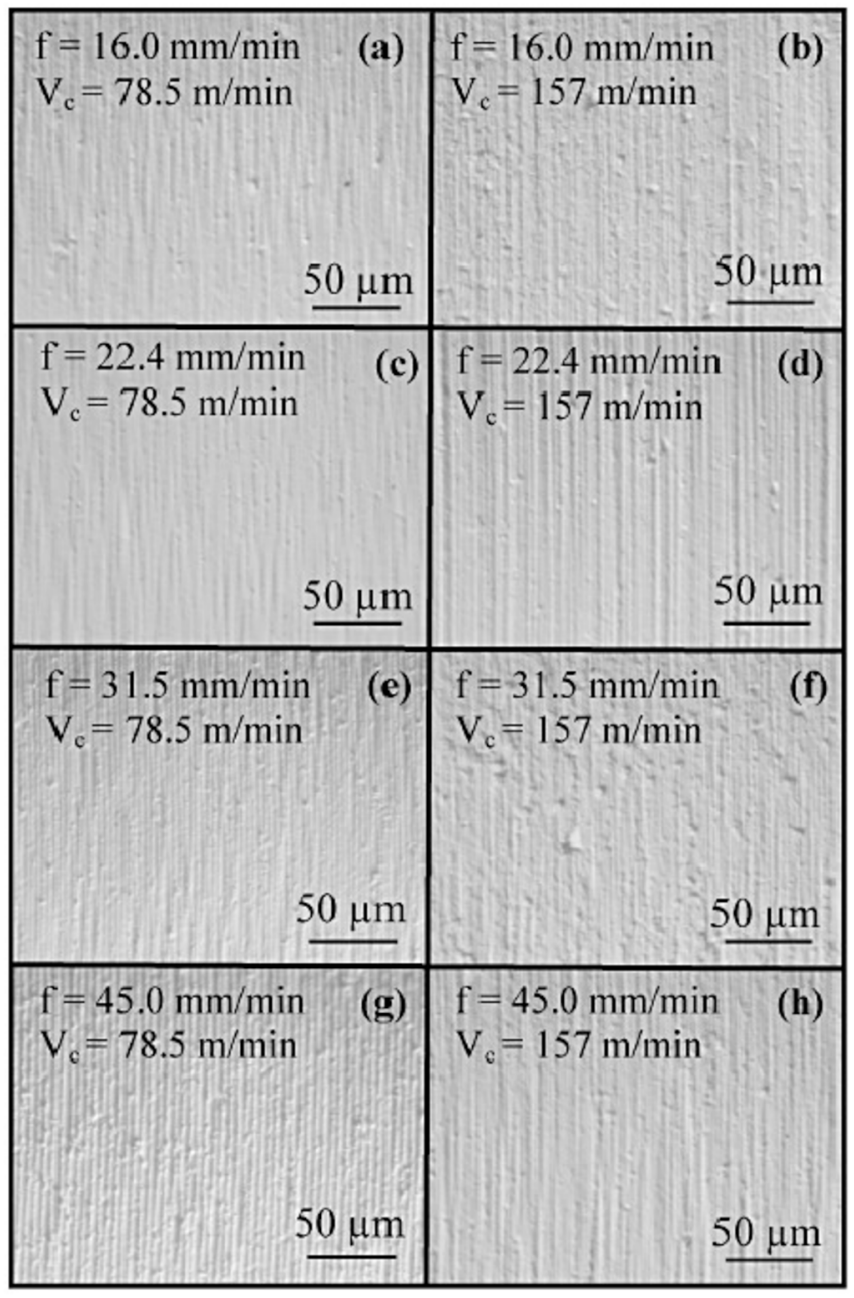

Fig. 4. Surfaces of green machined specimens with different finishing obtained by different machining conditions. 


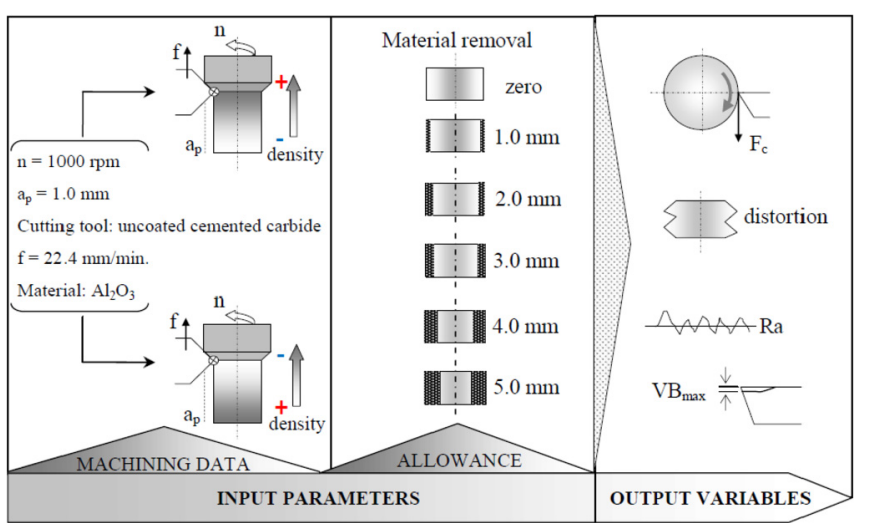

Fig. 5. Overview of the experimental parameters.

using a wax-based adhesive. The cylindrical cavity of the steel base was approximately the size of the piece diameter. In order to remove ceramic workpiece after machining the steel base was heated up to the wax melting point. The non-machined and machined workpices with the steel base are shown in Fig. 6.

As the portion less compacted of the piece as more compacted were machined and distortion in these regions were evaluated after sintering. The tests were carried out according to two basic procedures. First, the denser extremity of the workpiece (top part), relative to the contact with upper punch, was fixed to the steel base. So that, the extremity less dense of the workpiece (bottom part), which had contact with lower punch, was free to be machined. After, the portion with lower density (bottom part/lower punch) was fixed to the steel base and the portion with higher density (top part/upper punch) was free to be machined.

After selecting the cutting parameters, three green workpieces were machined from the top for each allowance value, as well as three green workpieces were machined from the bottom for each allowance value. Therefore, thirty specimens were used for the machining tests. Other three specimens were not machined to be used later as reference.

Both green and corresponding sintered workpieces had their diameters measured using a coordinate measurement machine (CMM), model Micro-Hite 3D manufactured by Tesa. The arithmetic average of the roughness profile ( $\mathrm{Ra}$ ) was measured using an optical profiling system (model Wyko NT 1100, Veeco, non-contact surface topography), since a conventional roughness tester with stylus scratches the surface of the green ceramic and thus provide an incorrect measure.

For a detailed analysis of the workpiece distortion, sixteen different positions (cross sections) were selected along the generatrix of each specimen, and in each one of these positions the

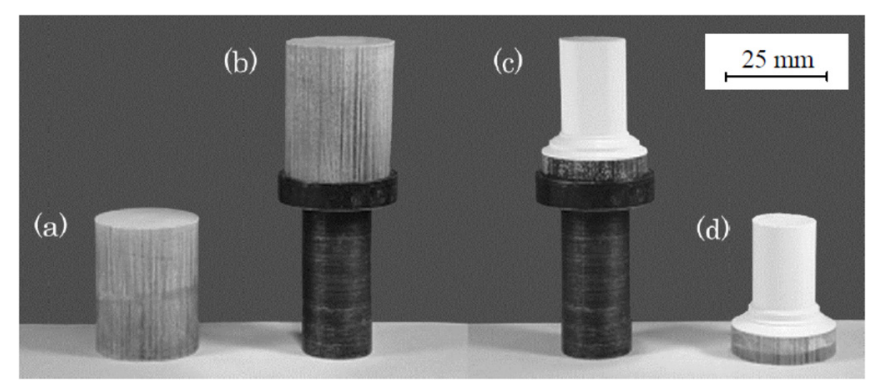

Fig. 6. Specimens (a) before embedded to the base, (b) embedded to the base, (c) machined and (d) detached from the base. specimen's diameter was measured by the CMM. The distance chosen between each position along the specimen's generatrix was $1.0 \mathrm{~mm}$. After sintering the distance between each position changed to $0.832 \mathrm{~mm}$, since the average linear shrinkage value found was $16.77 \%$. Fig. 7 illustrates the procedure for measurement of the shrinkage from non-machined and machined specimens.

The distortion calculation involves the value of the diameter difference between the largest measured position $\left(\mathrm{P}_{\mathrm{fG}}\right)$ and the lowest measured position $\left(\mathrm{P}_{\mathrm{iG}}\right)$ on the green workpiece $\left(\Delta_{\mathrm{G}}\right)$, as well as on the sintered workpiece $\left(\Delta_{S}\right)$. The total distortion value represents the distortion range $\left(\Delta_{R}\right)$ calculated from the diameter differences between the green and the sintered workpiece. So, the lower the $\Delta_{R}$ value, the lower the distortion. Equation (1) expresses the calculation of the distortion range, where larger values of $\Delta_{R}$ indicate an increasing of distortion and smaller values of $\Delta_{R}$ indicate a decreasing of distortion after sintering.

$\Delta_{\mathrm{R}}=\left(\mathrm{P}_{\mathrm{fS}}-\mathrm{P}_{\mathrm{iS}}\right)-\left(\mathrm{P}_{\mathrm{fG}}-\mathrm{P}_{\mathrm{iG}}\right)$

The sintering process was conducted in an electric furnace (Lindberg Blue chamber-like furnace), with a heating and cooling rate of $4.44{ }^{\circ} \mathrm{C} /$ hour at a temperature of $1600^{\circ} \mathrm{C}$ for $2 \mathrm{~h}$.

\section{Results and discussion}

According to the diameter measurements along the workpieces before and after sintering, it was verified that the largest shrinkages occurred in both top and bottom regions of the workpiece, where the compaction action by the punches are more efficient. However, comparing these two regions, the biggest shrinkages occurred in the lower end of the green workpiece under the lower punch influence. These results are consistent with the findings of Westerheide et al. (1996), Maier and Michaeli (1997) and Bencoe et al. (2008) who state that the bottom region presents the least apparent density in a workpiece obtained by single-action uniaxial pressing.

Fig. 8 shows the average shrinkage behavior of sintered nonmachined workpieces and after being machined with the biggest allowance selected of $5 \mathrm{~mm}$. Running across the 16 measuring positions in each end of the specimens, a significant difference in shrinkage caused by lower and upper punch was noted. In the case of upper punch acting, i.e. top of the workpiece, the shrinkage starts with higher values decreasing toward to the intermediary region of the specimen when they become relatively stable. In this part of the green workpiece the stabilization of shrinkage is reached much faster than in the lower punch side. For instance, considering the

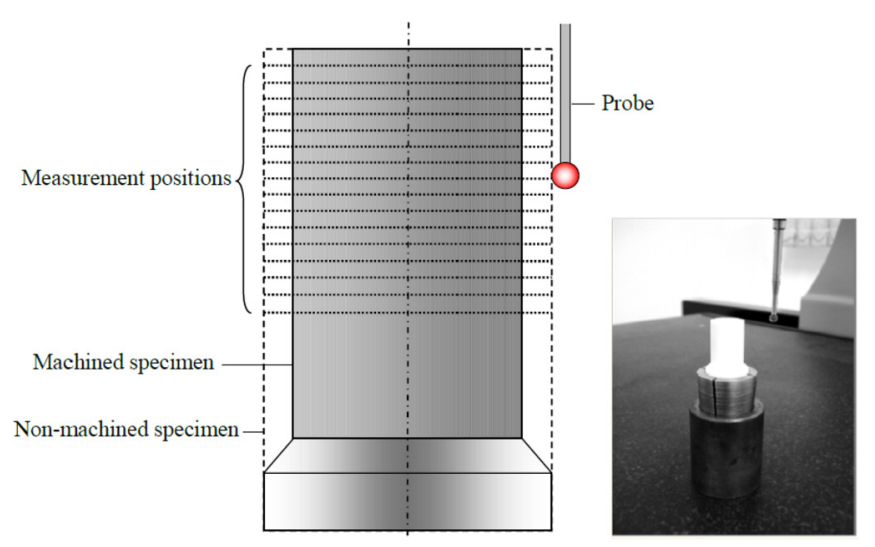

Fig. 7. Diameters measured in non-machined and machined specimens in green and sintered state. 


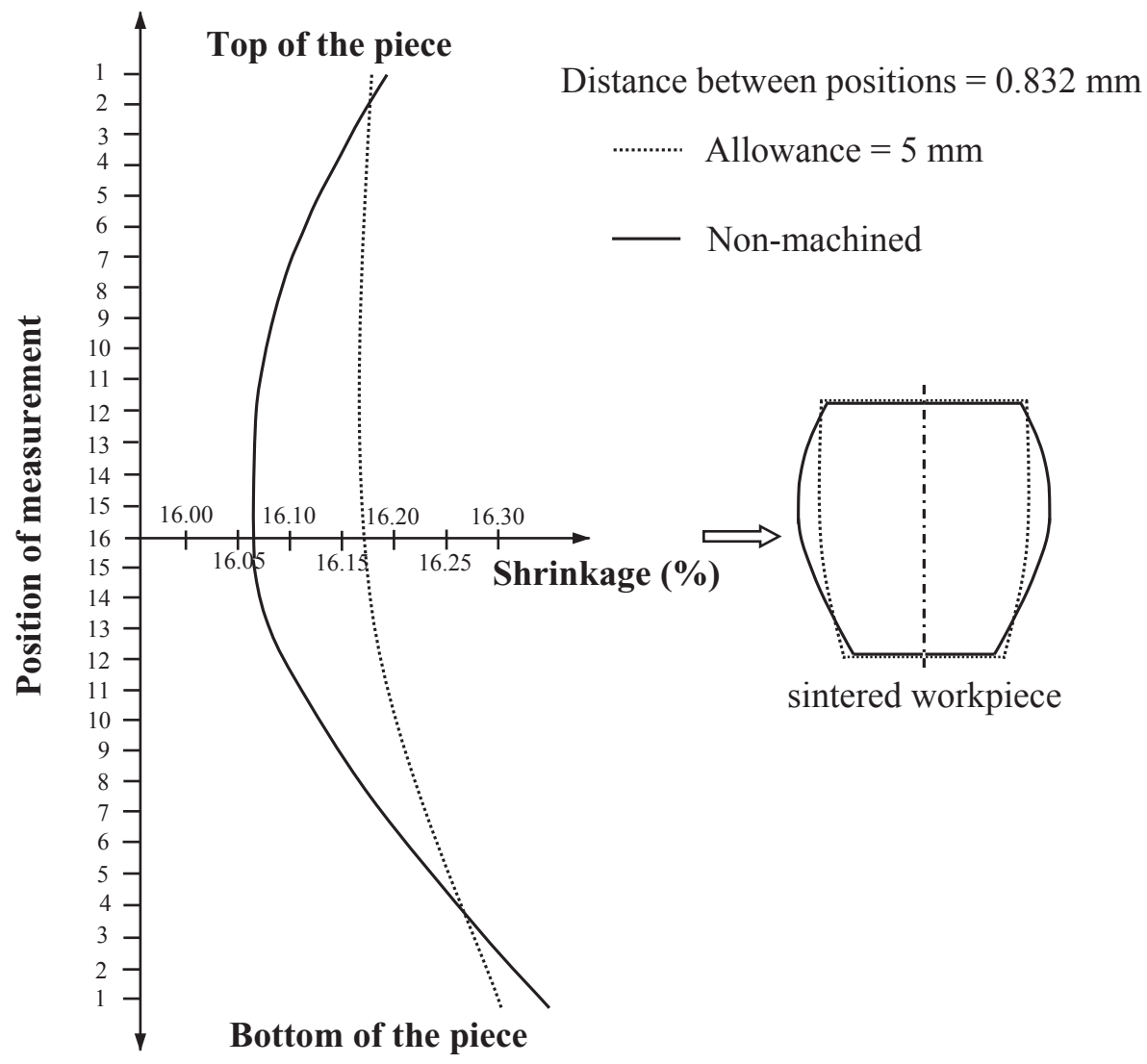

Fig. 8. Average shrinkage of non-machined and machined (removal of $5 \mathrm{~mm}$ ) green pieces after sintering.

sintered specimen, non-machined, the shrinkages in upper punch side become constants approximately in the eighth measuring position, while in the lower punch side there is only an indicative of stabilization in the fifteenth position of measuring. When the specimens are machined, this difference is more highlighted. In the upper punch side the allowance removal of $5 \mathrm{~mm}$ is able to propose constant shrinkage along the entire workpiece, including since the region of its end.

Fig. 8 also shows that the workpiece shrinkage after the allowance removal of $5 \mathrm{~mm}$ is higher than the workpiece non-machined. This effect can be attributed to the elimination of the greatest density gradients of the green workpiece, located in its outer parts, remaining densities of lower values and so bigger shrinkage. However, the remaining gradients are in lower number and more homogeneously distributed in the green workpiece obtaining lower dimensional range along the sintered workpiece which guarantees greater dimensional predictability, besides lower geometrical deviation as it will be seen next. Observing the values of diameters of green workpiece and sintered in Table 2 and Table 3, it is also possible to infer the same behavior obtained in the graphic of Fig. 8 .
Zipse (1997) observed that spite of machined and non-machined workpiece shrinkage to have been practicably equal, the machined workpiece shrinkage was much more uniform, indicating a result similar to Fig. 8 .

The calculation of distortion range $\left(\Delta_{R}\right)$ proposed in the work follows Equation (1), which involves the difference between the distortions of sintered and green workpieces $\left(\Delta_{S}-\Delta_{G}\right)$. First, sintered and green non-machined workpieces, (allowance $=0$ ) were evaluated. Also, green machined workpieces had removed material of five allowances different, afterward those green machined workpieces were sintered and their distortions were evaluated. The distortion range presented in Tables 2 and 3 indicates the effect of the allowance removal of green machined workpieces on the sintered workpieces. In this way, the lower the $\Delta_{R}$ value, the bigger the allowance removal effect in diminishing of sintered workpiece distortion.

The workpiece obtained directly from pressing (non-machined) has a deviation $(0.018 \mathrm{~mm})$ close to the average deviation of machined green workpieces $(0.020 \mathrm{~mm})$ as observed in Table 2 , which contains measures of the top region of green workpiece. In

Table 2

Distortion ranges at the top of the workpiece.

\begin{tabular}{|c|c|c|c|c|c|c|c|c|}
\hline \multicolumn{2}{|c|}{ Allowance (mm) } & $\mathrm{P}_{\mathrm{fG}}(\mathrm{mm})$ & $\mathrm{P}_{\mathrm{iG}}(\mathrm{mm})$ & $\mathrm{P}_{\mathrm{fS}}(\mathrm{mm})$ & $\mathrm{P}_{\mathrm{iS}}(\mathrm{mm})$ & $\Delta_{\mathrm{G}}(\mathrm{mm})$ & $\Delta_{\mathrm{S}}(\mathrm{mm})$ & $\Delta_{\mathrm{R}}(\mathrm{mm})$ \\
\hline \multicolumn{2}{|c|}{0 (Non-machined) } & 25.134 & 25.116 & 21.105 & 21.052 & 0.018 & 0.053 & 0.035 \\
\hline \multirow[t]{5}{*}{ Machined } & 1 & 23.425 & 23.403 & 19.657 & 19.635 & 0.022 & 0.028 & 0.006 \\
\hline & 2 & 21.452 & 21.430 & 17.979 & 18.005 & 0.022 & 0.026 & 0.004 \\
\hline & 3 & 19.395 & 19.376 & 16.260 & 16.238 & 0.019 & 0.022 & 0.003 \\
\hline & 4 & 17.415 & 17.395 & 14.562 & 14.539 & 0.020 & 0.023 & 0.003 \\
\hline & 5 & 15.637 & 15.618 & 13.100 & 13.080 & 0.019 & 0.020 & 0.001 \\
\hline
\end{tabular}


Table 3

Distortion ranges at the bottom of the workpiece.

\begin{tabular}{|c|c|c|c|c|c|c|c|c|}
\hline \multicolumn{2}{|c|}{ Allowance (mm) } & $\mathrm{P}_{\mathrm{fG}}(\mathrm{mm})$ & $\mathrm{P}_{\mathrm{iG}}(\mathrm{mm})$ & $\mathrm{P}_{\mathrm{fS}}(\mathrm{mm})$ & $\mathrm{P}_{\mathrm{iS}}(\mathrm{mm})$ & $\Delta_{\mathrm{G}}(\mathrm{mm})$ & $\Delta_{\mathrm{S}}(\mathrm{mm})$ & $\Delta_{\mathrm{R}}(\mathrm{mm})$ \\
\hline \multicolumn{2}{|c|}{0 (Non-machined) } & 25.136 & 25.125 & 21.075 & 20.970 & 0.011 & 0.105 & 0.094 \\
\hline \multirow[t]{5}{*}{ Machined } & 1 & 23.352 & 23.336 & 19.527 & 19.462 & 0.016 & 0.065 & 0.049 \\
\hline & 2 & 21.255 & 21.235 & 17.788 & 17.735 & 0.020 & 0.053 & 0.033 \\
\hline & 3 & 19.305 & 19.289 & 16.156 & 16.115 & 0.016 & 0.041 & 0.025 \\
\hline & 4 & 17.261 & 17.245 & 14.455 & 14.421 & 0.016 & 0.034 & 0.018 \\
\hline & 5 & 15.274 & 15.243 & 12.758 & 12.732 & 0.031 & 0.026 & -0.005 \\
\hline
\end{tabular}

the case of the inferior region (Table 3), the average deviation of machined green workpieces $(0.024 \mathrm{~mm})$ is almost the double of non-machined workpiece $(0.011 \mathrm{~mm})$.

It can be observed, according to the values from both tables, that the machined green workpieces deviations are kept lower and practically constant with the change of allowance removal while the sintered workpieces deviations are higher, but decrease with increasing allowance removal. In the case of inferior region of the workpiece, it is necessary to reach the allowance removal of $5 \mathrm{~mm}$ to achieve distortion levels of sintered workpiece $(0.026 \mathrm{~mm})$ close to the distortion obtained in the workpiece top region. In general, this behavior can be attributed to the most intense densification and the material structure more homogeneous of the workpiece top region in relation to its bottom region.

In Fig. 9 it is possible to observe that after sintering the greatest distortion occurs on non-machined workpiece, highlightly in the bottom region $(0.094 \mathrm{~mm})$. After the progressive material removal the deviation continuously decreases reaching $0.008 \mathrm{~mm}$ with the machining of $5 \mathrm{~mm}$ allowance, in the case of the workpiece bottom region. In the top region, the deviation dramatically decreases already with the material removal of $1 \mathrm{~mm}$ and remains in relatively low levels until reaches a minimum value of $0.001 \mathrm{~mm}$ with the machining of $5 \mathrm{~mm}$ allowance. In other words, the allowance removal effect on the workpiece distortion is more significant in the top than the bottom region. This effect can be credited to the extraction of material portion with higher concentration of density gradients confined in a small outside layer of workpiece top part. Once extracted, the remaining workpiece contains less density variations.

Fig. 10 shows the behavior of distortion reduction of sintered workpieces for each of five removal material volumes, given in percentages. The volumes of $15,30,42,54$ and $64 \%$ correspond to the removed allowance of $1,2,3,4$ and $5 \mathrm{~mm}$, respectively.

The deviation of the bottom part of the workpiece decreases $48 \%$ in relation to the non-machined workpiece with the removal of $1 \mathrm{~mm}$ of material (15\% removed volume) and $65,73,81$ and $91 \%$

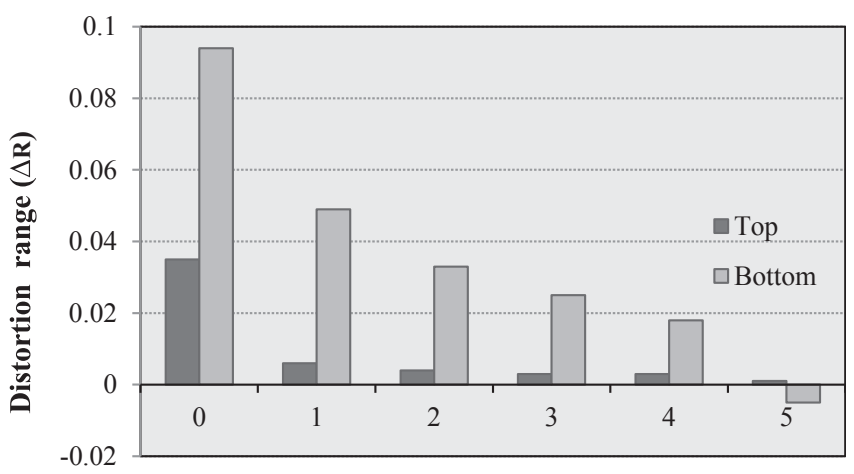

Allowance (mm) with the corresponding machining of $2,3,4$, and $5 \mathrm{~mm}$ of allowance. On the other hand, the top part of the workpiece already reaches $82 \%$ of distortion reduction with removal of $1 \mathrm{~mm}$ of allowance and 88,91, 91, and 97\% with allowances of 2, 3, 4 and $5 \mathrm{~mm}$, successively.

In Fig. 10 can be inferred that would be necessary to remove $54 \%$ of the volume of the green ceramic bottom part in order to reach the same level of distortion reduction of the top part obtained with only $15 \%$ of the volume removed.

According to these results, it is observed that the current practice of machining a green ceramic piece under a unique allowance removal value produces distortion deviations significantly different on both ends of the sintered piece and, therefore, it is not an optimized technique. This important outcome has never been discussed neither by academia nor industry of green ceramic machining.

In the tests, a fresh cutting edge was used for each value of allowance. Thus, cutting force and flank wear were accompanied both to the cutting edge which removed an allowance of $5 \mathrm{~mm}$, where five passes were necessary, and to the edge which removed $1 \mathrm{~mm}$, where only one pass was given.

The graphic in Fig. 11 shows the average cutting force $(\mathrm{Fc})$ for each of the five allowance values. As can be seen, Fc continuously rise up with the increase of allowance removal mainly due to the growing of the cutting tool wear as a consequence of several passes necessary to remove each of the allowances. In relation to the bottom part, the highest cutting force occurred during the machining of the top part of the workpieces. These results can be attributed to the maximum material densities and consequently, to the greatest cohesion of ceramic particles in such region. By removing $1 \mathrm{~mm}$ allowance for both top and bottom part can be noticed no significant difference in Fc. According to the progressive increasing of allowance removal of $2 \mathrm{~mm}, 3 \mathrm{~mm}$, and $4 \mathrm{~mm}$ there is a highlighted growth around 30\% in cutting force for machining the top parts and $17 \%$ for the $5 \mathrm{~mm}$ allowance removal.

Maximum flank wear (VBmax) of the cutting tool is presented in

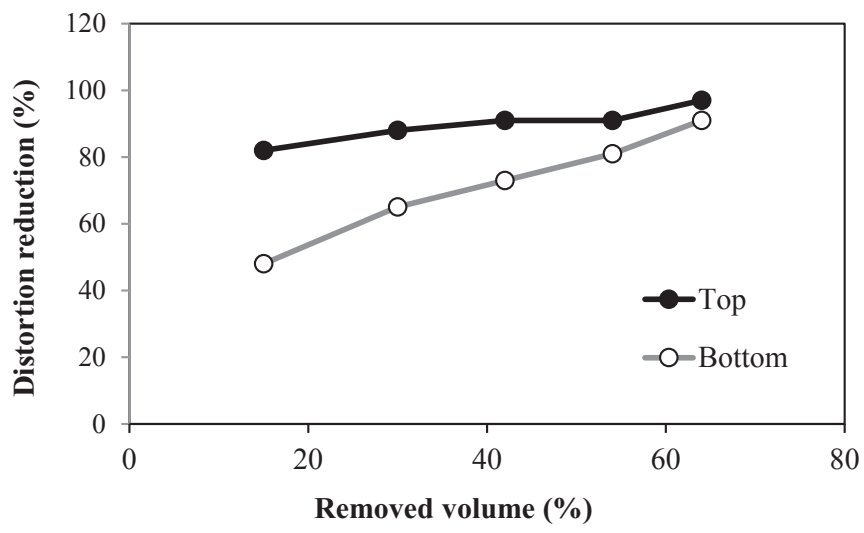

Fig. 9. Distortion range $\left(\Delta_{R}\right)$ for different removed allowance.

Fig. 10. Percentage of distortion reduction for different removed material volume 


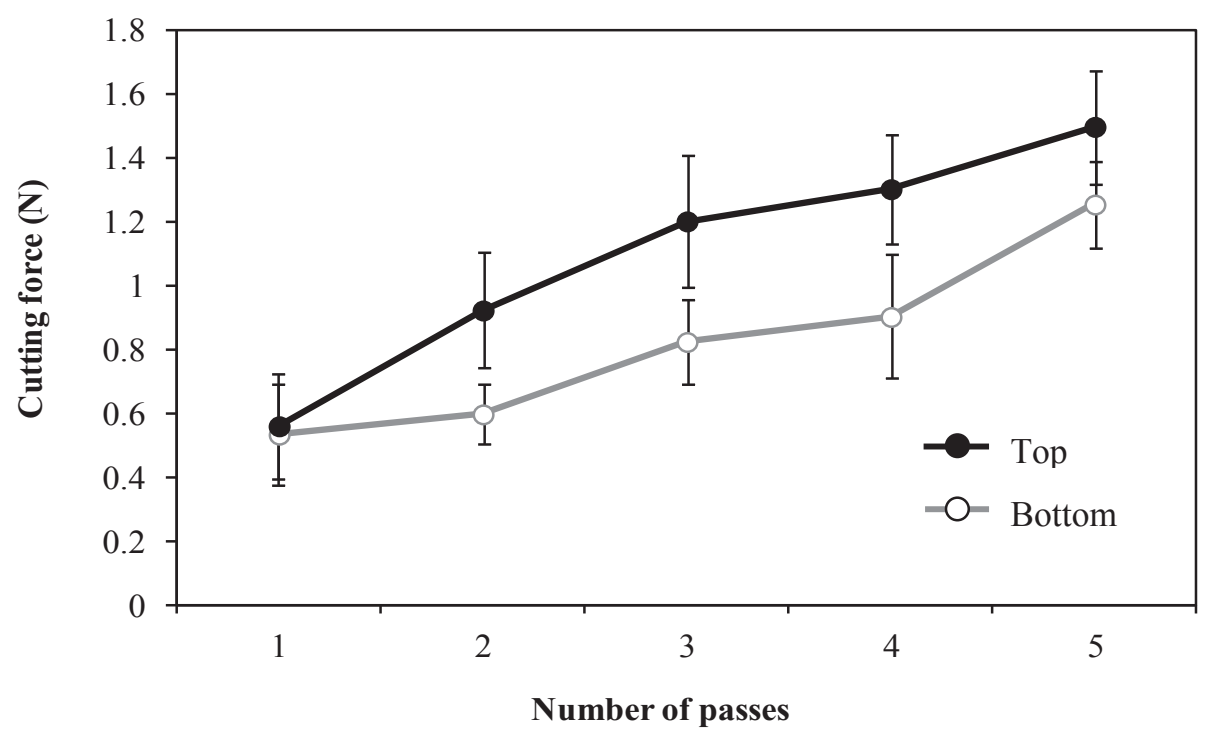

Fig. 11. Cutting force for the different allowance values.

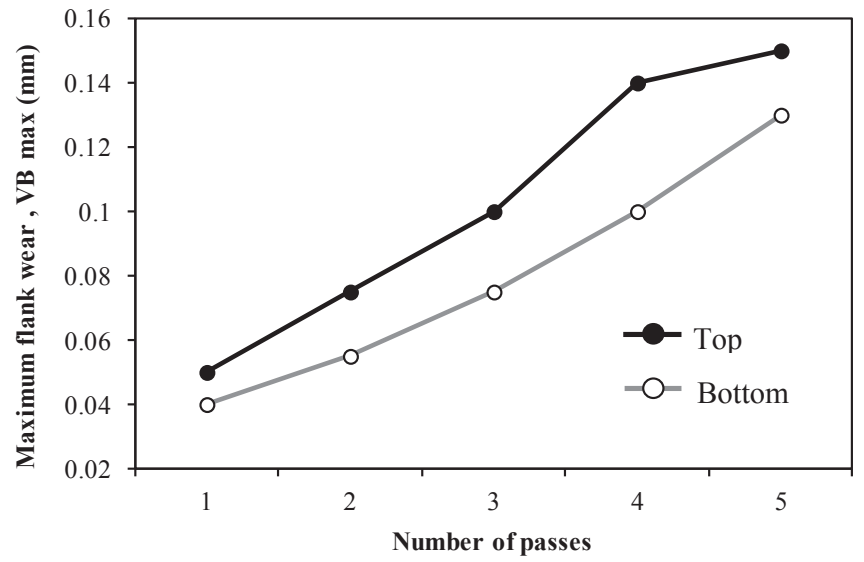

Fig. 12. Cutting tool wear (VBmax) for different allowance values.

Fig. 12. By machining a denser volume the inserts worn out more rapidly due to superior mechanical properties of the workpieces' top part. It can be observed that the bottom machining promotes approximately the same tool wear values of the top machining one pass later. The lower difference occurred with the $1 \mathrm{~mm}$ allowance removal. By means of allowance removal increment was observed a strong increase on the tool wear, with values approximately $25 \%$ higher during the machining of the workpiece top part in relation to the bottom part, and $13 \%$ increasing for $5 \mathrm{~mm}$ allowance removal.

Fig. 13 shows the images of (a) new cutting tool, (b) after removing an allowance of $5 \mathrm{~mm}$ of the top region and (c) workpiece bottom. The cutting tools wear in the machining of metallic materials occur, mainly, due to the mechanisms of abrasion, diffusion and adherence (Cook, 1973). These two latter mechanisms are motivated by chemical affinity between the cutting tool and workpiece materials associated to the high stresses and high temperatures in the cutting zone (Shaw, 2005). The images of the worn tools suggest mainly the presence of abrasive mechanism, once just parallel scratches perpendicular to the main cutting edge produced by workpiece's ceramic particles are seen. In fact, the machining conditions do not favor any other wear mechanisms because both temperature and stresses are quite low. This statement can be corroborated by the analysis of chemical composition using the
Energy-dispersive X-ray spectroscopy (EDS) by comparing fresh and used tools which presented the chemical composition, confirming the absence of adhered workpiece material on the cutting tool, as observed in Fig. 14.

According to Ng et al. (2006), abrasive particles (chips) produced in green machining can stick on the workpiece surface resulting in incremental cutting tool wear. However, this situation was not observed in this study.

Fig. 15 shows SEM images of the chips produced by turning. It can be observed that debris were mainly in powder form of small agglomerates of randomly shapes and they have no geometrical similarity with the powder obtained from the spray dryer method previously presented in Fig. 2.

Fig. 16 shows the surface roughness values of green machined workpieces set against cutting tool flank wear (VBmax) and their corresponding surface roughness after sintering. Each point of the graphic curves indicates the measurement performed after allowance removal of $1.0,2.0,3.0,4.0$, and $5.0 \mathrm{~mm}$, except the points relative to the $\mathrm{VBmax}=0$, which there are no material removal. Firstly, it is noted that the surface roughness of non-machined $(\mathrm{VBmax}=0)$ and machined green workpieces significantly decreases after sintering. In fact, the surface roughness improves with the volume retraction in addition to the ceramic diffusion mechanism promoted during sintering, as mentioned by Bukvic et al. (2012).

Fig. 16 points out that the non-machined green workpiece $(\mathrm{VBmax}=0)$ undergoes a surface roughness reduction of approximately $15 \%$ after sintering in both top and bottom workpiece parts. However, the two parts of the workpiece present different surface roughness values in both green and sintered workpiece.

In relation to the green machining of the bottom part, the surface roughness values are kept close to the compacted workpieces, even with the progressive cutting tool wear. After sintering, it is observed that the surface roughness rises with the increase in the cutting tool wear, unlike the behavior nearly constant of surface roughness in green machining, which is verified even with the progressive cutting tool wear. Besides, the lowest value of surface roughness corresponds to the lowest cutting tool wear (VBmax $=0.04 \mathrm{~mm})$, measured after first amount of allowance removed $(1.0 \mathrm{~mm})$.

With regard to the green machining of the top part, the surface 


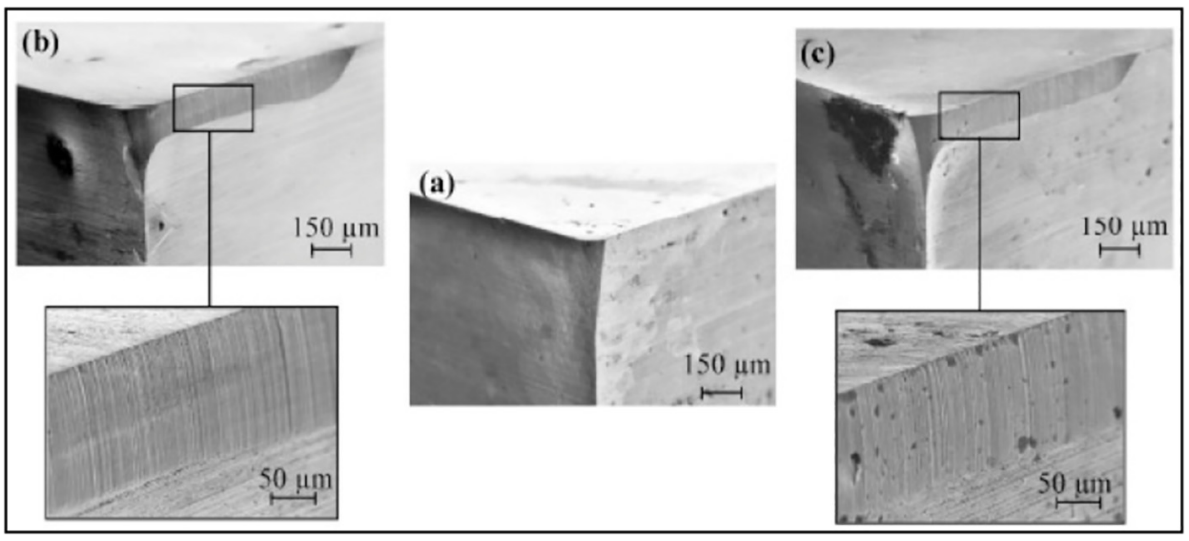

Fig. 13. Cutting tool: (a) new, (b) after removing $5 \mathrm{~mm}$ of the top region and (c) workpiece bottom.
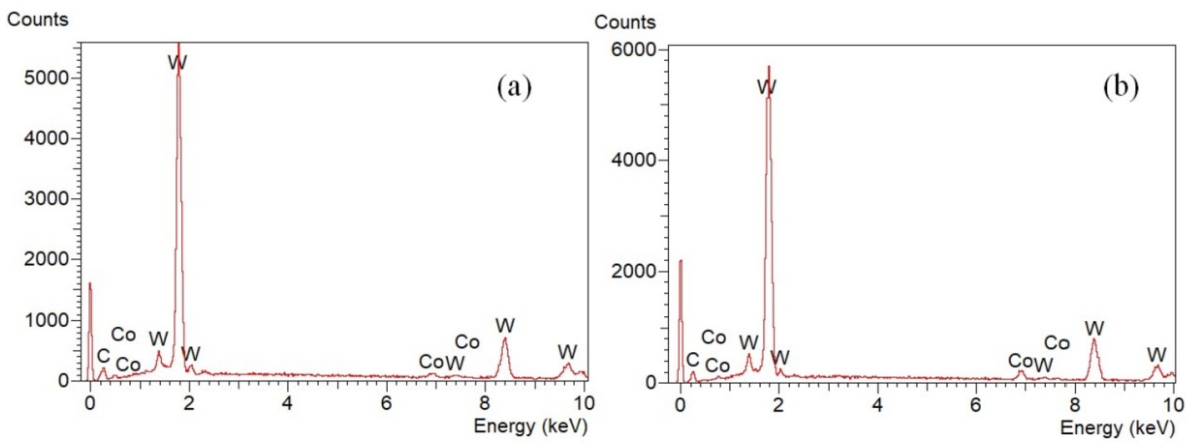

Fig. 14. EDS of the surface of the (a) new tool and (b) worn flank region.

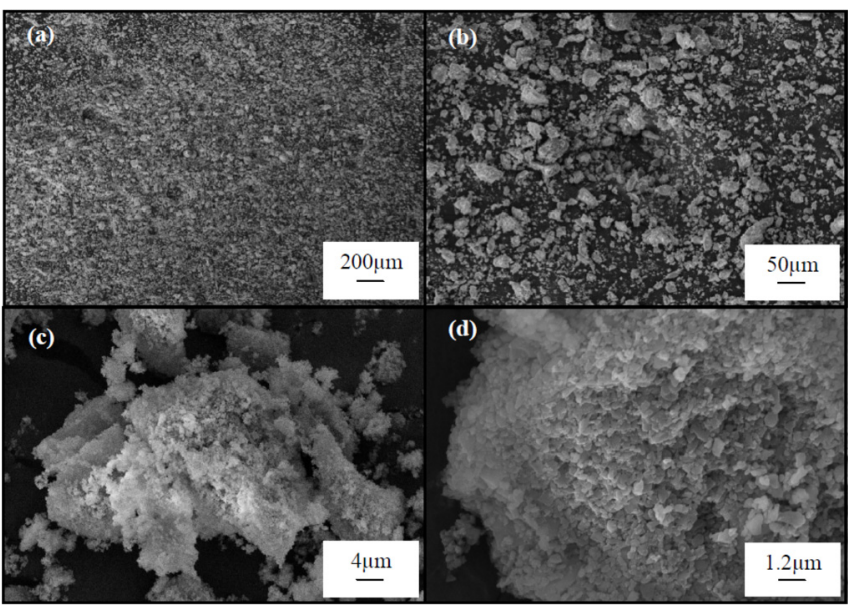

Fig. 15. Magnification of chips: (a) 100×; (b) 500X; (c) 5000X; and (d) 20000X.

roughness decreases significantly in relation to the non-machined green workpiece after the removal of smallest allowance $(1.0 \mathrm{~mm})$, when the cutting tool wear was just $0.05 \mathrm{~mm}$. From this point, the surface roughness rises with the increase in the cutting tool wear. The lowest values of surface roughness found in the green workpiece top part in relation to the its bottom part can be credited to the concentration of higher density gradients and the greatest cohesion among the alumina particles which minimize the superficial defects, as suggested by Zipse (1997). After sintering, the surface roughness of top part follows, to a large extent, the behavior of machined green workpiece. It is interesting to highlight that the

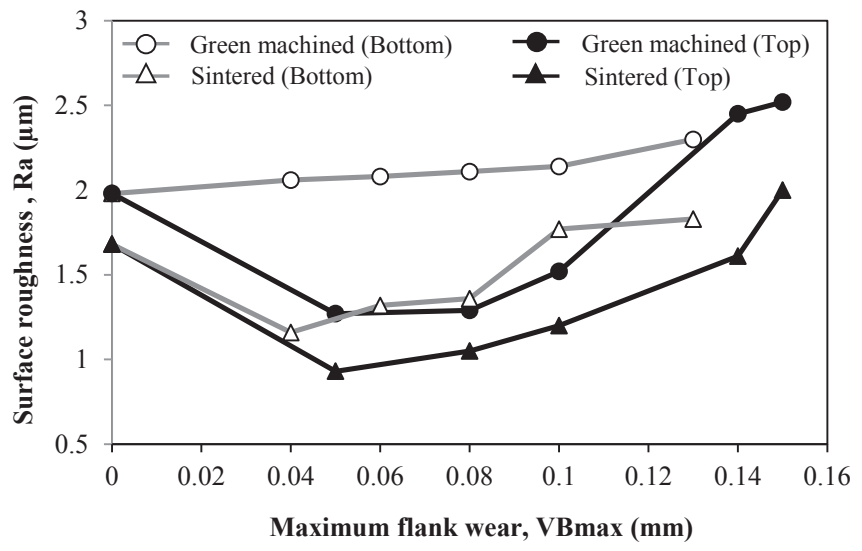

Fig. 16. Roughness (Ra) of green and sintered workpieces under tool wear $\left(\mathrm{VB}_{\max }\right)$.

two lowest cutting tool wear (VBmax $=0.05 \mathrm{~mm}$ and $\mathrm{VBmax}=0.08 \mathrm{~mm}$ ) produce practicably the same surface roughness values, but after the sintering their surface roughness are different, which higher value is due to the lager cutting tool wear.

From the results of Fig. 16, it can be inferred that the sintered workpiece surface roughness in both bottom and top part is more influenced by the cutting tool wear, which is also associated to the amount of allowance removed, than by surface roughness of green machined workpiece. In this way, for reaching low surface roughness values in sintered workpieces both cutting tool wear and allowance removal must be small. On the other hand, if low distortions are sought, so greater allowance values must be removed, such as discussed in the results from Figs. 8-10. 


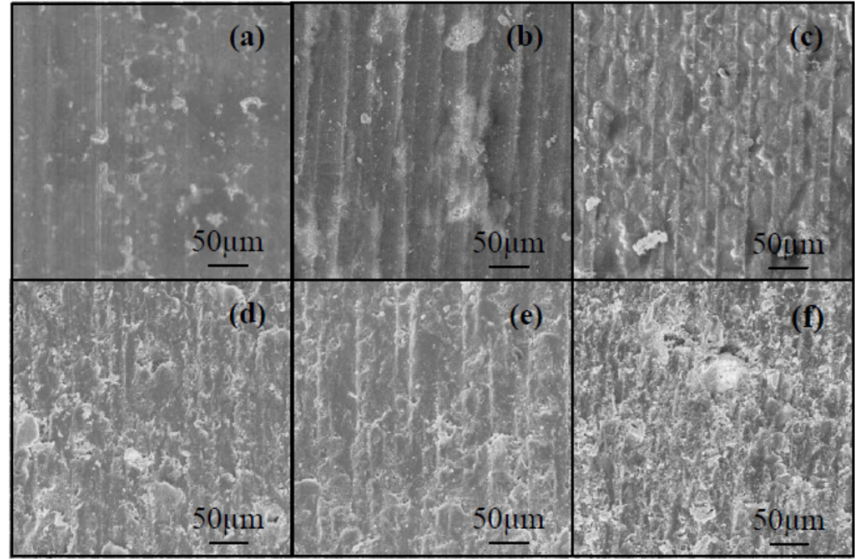

Fig. 17. SEM images of the top part of green workpiece (a) non-machined and machined with allowances of (b) $1.0 \mathrm{~mm}$, (c) $2.0 \mathrm{~mm}$, (d) $3.0 \mathrm{~mm}$, (e) $4.0 \mathrm{~mm}$, and (f) $5.0 \mathrm{~mm}$.

Fig. 17 shows the SEM images of non-machined and machined green workpieces. The parallel scratches on the non-machined workpiece were left by the die during the manufacture of the workpiece (Fig. 17a). Empty spaces among the contours of the particle agglomerates can also be seen. On the other images, (Fig. 17b-f), the machined workpiece surfaces with allowances of $1.0,2.0,3.0,4.0$ and $5.0 \mathrm{~mm}$, are shown respectively. They present larger scratches, created by the cutting tool tip during the machining process. The visual aspect of their surfaces becomes rougher as the wear of the tool and the cutting force progressively increase, especially for the last three conditions (d, e and f). Surface roughness deterioration can be credited to the introduction of defects, such as loosening, dislodgment and pulling out of particle agglomerates, leading to surfaces that look like a "fish scales", as can be seen in Fig. 17.

Fig. 18 shows the surfaces after sintering and the response to this densification process. Considering that it promotes grain growth, it was obtained a uniformity in the finishing visual aspect. This affirmative can be justified by the reduction in surface roughness after sintering. The image of the non-machined sintered workpiece (Fig. 18a) shows the drastically reduction of empty sites on the surface particles for this magnification, previously seen on the green workpiece. In images (Fig. 18b and c) of the sintered top

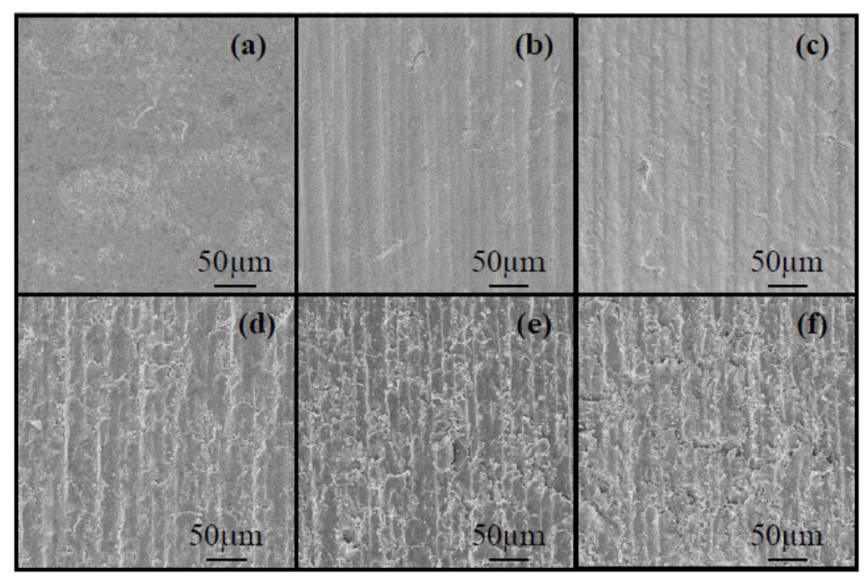

Fig. 18. SEM images of the top part of sintered workpiece (a) non-machined and machined with allowances of (b) $1.0 \mathrm{~mm}$, (c) $2.0 \mathrm{~mm}$, (d) $3.0 \mathrm{~mm}$, (e) $4.0 \mathrm{~mm}$, and (f) $5.0 \mathrm{~mm}$.

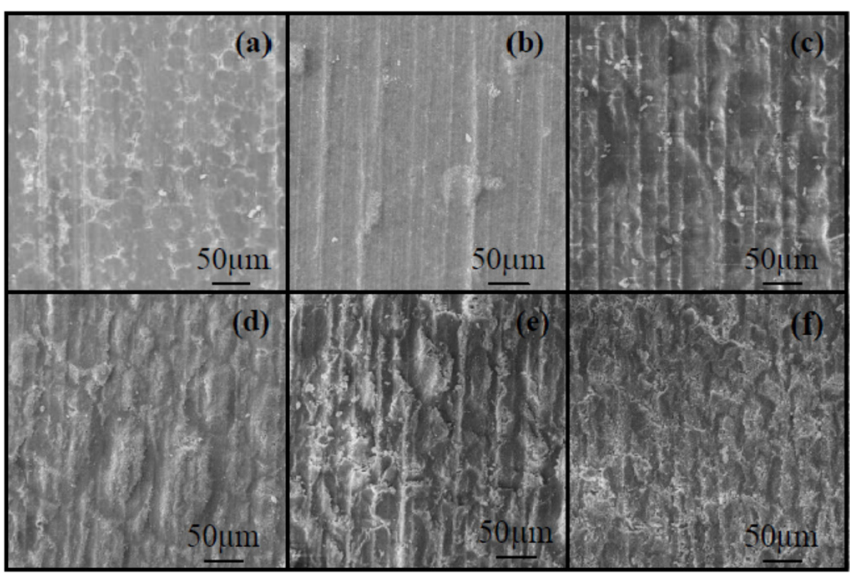

Fig. 19. SEM images of the bottom part of green workpiece (a) non-machined and machined with allowances of (b) $1.0 \mathrm{~mm}$, (c) $2.0 \mathrm{~mm}$, (d) $3.0 \mathrm{~mm}$, (e) $4.0 \mathrm{~mm}$, and (f) $5.0 \mathrm{~mm}$.

machined workpieces, greater uniformity of the surface can be seen. In the images (Fig. 18d-f), with the accentuated wear of the tool, the "fish scale" aspect emerged. In these three last machining conditions, the sintering mechanisms was not enough for repairing the surface irregularities left by the worn tool as efficiently as occurred for $1 \mathrm{~mm}$ and $2 \mathrm{~mm}$ allowance removal.

SEM images of non-machined and machined bottom parts of green workpieces can be seen in Fig. 19. A non-machined workpiece presents the scratches left by the die (Fig. 19a). The contours of ceramic agglomerates are clearly seen, indicating that the material in this region was less compacted than the top part (Fig. 17a). The images of Fig. 19 (b, c, d, e, and f) show the workpieces that have undergone allowance removals of $1.0,2.0,3.0,4.0$, and $5.0 \mathrm{~mm}$, respectively. It is possible to observe the scratches left by the cutting tool tip that progressively suffers wear influencing in the loss of uniformity of the surfaces. The images of Fig. 19 (e and f) depict the possible introduction of damages, such as loose, displaced, and dragged ceramic agglomerates, creating a fish scale-like surface.

Fig. 20 shows the surfaces of the non-machined and bottom machined workpieces after the sintering process. The bottom surfaces presented the same sintering characteristics previously described for the top region. There is a predominant uniformity in the finishing visual aspect. This statement can be justified by the

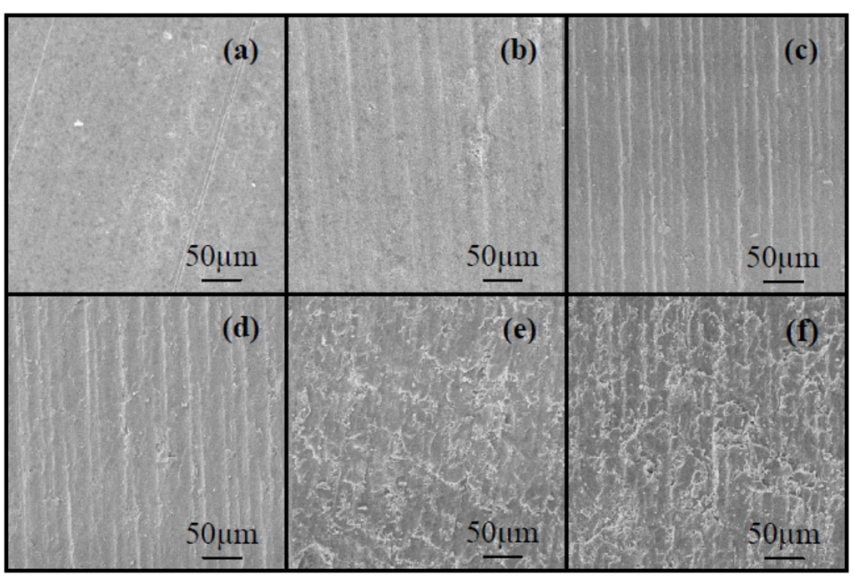

Fig. 20. SEM images of the bottom part of sintered workpiece (a) non-machined and machined with allowances of (b) $1.0 \mathrm{~mm}$, (c) $2.0 \mathrm{~mm}$, (d) $3.0 \mathrm{~mm}$, (e) $4.0 \mathrm{~mm}$, and (f) $5.0 \mathrm{~mm}$. 
reduction on the surface roughness after sintering. The image in Fig. 20a of the non-machined sintered workpiece showed the considerably reduction of pores previously seen on the green workpiece (Fig. 19a). In the images of Fig. 20 (b, c, and d) of the machined and sintered workpieces, a better consistency of the surface finishing can be perceived. The fish scale-like occurred in the images of Fig. 20 (e and f), which the accentuated wear of the tool is believed to be the responsible for compromising surface integrity.

\section{Conclusions}

Based on the results obtained in this study, it can be briefly concluded that:

The reduction of the number of density gradients of a green ceramic body by single-action pressing decreases the sintered piece distortion. Thus, the foresight of allowance machining of a green ceramic piece and its elimination by chip removal processes is a good alternative for improving the quality of a ceramic product, since that the outer regions concentrate the most density ranges which decrease towards to the center of the green part.

The distortion of machined specimens with an allowance of $5.0 \mathrm{~mm}$ decreased significantly after sintering.

After sintering, the denser volume of the compacted workpiece due to the action of the upper punch presents a lower distortion than the region of the workpiece submitted to the bottom one. With progressive allowance removal the distortion in both regions is decreased, but the top workpiece presents a highlighted reduction $(82 \%)$ since the removal of an allowance of $1,0 \mathrm{~mm}$ (the lowest value used in the study), while that for this same value the distortion reduction of the bottom region was much lower (48\%).

Once the distortion values of both opposite regions of green workpiece are significantly different, the amount of machining allowance necessary to produces the lowest deviations must be considered in relation to workpiece bottom region, which is that where the highest distortions are produced. Likewise, if it is necessary to carry out any geometric characteristic in the green piece it is preferable that it is done at the top part. Such method is neither mentioned in advanced ceramic literature nor practiced on the shop floor.

Despite of the lowest geometric deviation of the sintered workpieces obtained by means of green machining, they suffer higher shrinkage than non-machined ones. That might be considered contradictory, but regions having lower number of density gradients with minor density values than those found in outer layers of the green workpiece are reached with the progressive allowance removal.

The quality of surface finishing of the green ceramic has a direct influence on the sintered piece, in which the green machining is always beneficial for reducing surface roughness of the sintered component. Furthermore, the cutting tool wear is responsible for the surface roughness of green machined pieces, and the wear mechanism is exclusively abrasive in uncoated cemented carbide tools. Hence, the lowest surface roughness is obtained in the workpiece top region when the cutting tool is less worn.

With the substantial reduction in the distortion of sintered workpieces due to the green machining, the use of ceramic parts with no necessity of final machining (hard ceramic machining) becomes feasible in some applications which the technical specification permits. In this case, the surface roughness of the green piece gains even greater importance.

Finally, it can be concluded that green machining is remarkable not only for obtaining complex shapes of pieces with higher removal rates due to lower mechanical strength at a stage prior to sintering or then approaching them as much as possible to the final dimensions intended for the sintered piece (near net shape technique) widely spread in the literature, but also to reduce distortion and improve surface roughness. However, the regions with different density values, the adequate allowance removal value and the control of cutting tool wear must be considered, as verified in this study.

\section{Acknowledgements}

The authors would like to thank Fundação de Amparo à Pesquisa do Estado de São Paulo (FAPESP), Brazil, by the scholarship grant $(10 / 05792-4)$.

\section{References}

Ajjarupu, S.K., Fesperman, R.R., Patten, J.A., Cherukuri, H.P., 2004. Experimental and numerical investigation of ductile regime machining of silicon nitride. In: AIP Conf. Proc. Columb. U. S. A., June 13-17, pp. 1377-1383.

Albaro, J.L.A., 2000. The Pressing operation: technical considerations and its industrial application. Part V: pressing phase description. Ind. Ceram. 6 (3), 26-32.

Bencoe, D.N., DiAntonio, C.B., Ewsuk, K.G., 2008. Density Gradient Evolution in Alumina Powder Compacts during Sintering. Sandia National Laboratories, Albuquerque, NM, 87185-1349.

Blackley, W.S., Scattergood, R.O., 1991. Ductile regime machining model for diamond turning of brittle materials. Precis. Eng. 13 (2), 95-103.

Blacley, W.S., Scattergood, R.O., 1994. Chip topography for ductile-regime machining of germanium. ASME J. Eng. Ind. 116, 263-266.

Bukvic, G., Sanchez, L.E.A., Fortulan, C.A., Fiocchi, A.A., Marinescu, D., 2012. Green machining oriented to diminish density gradient for minimization of distortion in advanced ceramics. Mach. Sci. Technol. 16 (2), 228-246.

Burton, C.M., Crook, B., Scaife, H., Evans, G.S., Barber, C.M., 2012. Systematic review of respiratory outbreaks associated with exposure to water-based metalworking fluids. Ann. Occup. Hyg. 56 (4), 374-388.

Chang, C., Kuo, C., 2007. An investigation of laser-assisted machining of Al2O3 ceramics planing. Int. J. Mach. Tools Manuf. 47, 452-461.

Cook, N.H., 1973. Tool wear and tool life. J. Eng. Ind. 95 (4), 931-938.

Debnath, S., Reddy, M.M., Yi, Q.S., 2014. Environmental friendly cutting fluids and cooling techniques in machining: a review. J. Clean. Prod. 83, 33-47.

Desfontaines, M., Jorand, Y., Gonon, M., Fantozzi, G., 2005. Characterisation of the green machinability desfontaines M, Jorand Y, Gonon M, fantozzi G. Characterisation of the green machinability of AlN powder compacts. J. Eur. Ceram. Soc. 25, 781-791.

Diarra, H., Mazel, V., Boillon, A., Rehault, L., Busignies, V., Bureau, S., Tchoreloff, P., 2012. Finite element method (FEM) modeling of the powder compaction of cosmetic products: comparison between simulated and experimental results. Powder Technol. 224, 233-240.

Ekabaram, V., 2008. Optimization of Green Ceramic Grinding. Thesis. The University of Toledo, USA.

Frenning, G., 2007. Analysis of pharmaceutical powder compaction using multiplicative hyperelasto-plastic theory. Powder Technol. 172, 103-112.

German, R.M., 1994. Powder Metallurgy Science, second ed. Metal Powder Industries Federation, Princeton, New Jersey, USA.

Goindi, G.S., Sarkar, P., 2017. Dry machining: a step towards sustainable machining challenges and future directions. J. Clean. Prod. 165, 1557-1571.

Gouveia, P.F. Schabbach, L.M., Souza, J.C.M., Henriques, B., Labrincha, J.A., Silva, F.S. Fredel, M.C., Mesquita-Guimarães, J., 2017. New perspectives for recycling dental zirconia waste resulting from CAD/CAM manufacturing process. J. Clean. Prod. 152, 454-463.

Kitagawa, T., Maekawa, K., 1990. Plasma hot machining for new engineering materials. Wear 139, 251-267.

Klock, F., Pähter, D., Schippers, C., Schmidt, C., 2001. Green machining of aluminum oxides ceramics. In: 7th International Symposium Ceramic Materials and Components for Engines. June 19-21, Geslar, 371-376.

Lee, T.C., Lau, W.S., 1991. Some characteristics of electrical discharge machining of conductive ceramics. Mater. Manuf. Process. 6 (4), 635-648.

Leriche, A., Moortgat, G., Cambier, F., Homerin, P., Thevenot, F., Orange, G. Fantozzi, G., 1988. Preparation and microstructure of zirconia toughened alumina ceramics. Advances in ceramics. Science and technology of zirconia III Ed. Am. Ceram. Soc. Inc 24, 1033-1041.

López de Lacalle, L.N., Sánchez, J.A., Lamikiz, A., Celaya, A., 2004. Plasma assisted milling of heat-resistant superalloys. ASME J. Manuf. Sci. Eng. 126, 274-285.

Maier, H.R., Michaeli, N., 1997. Green machining of alumina. Key Eng. Mat. 132 (136), 436-439.

Malkin, S., Ritter, J.E., 1989. Grinding mechanisms and strength degradation for ceramics. ASME J. Eng. Ind. 1, 167-174.

Marinescu, I.D., Hitchner, M., Uhlmann, E., Inasaki, I., 2007. Handbook of Machining with Grinding Wheels, first ed. CRC Press, Boca Raton, FL, USA.

Marshall, D.B., Evans, A.G., Yakub, B.T.K., Tien, J.W., Kino, G.S., 1983. The nature of machining damage in brittle materials. Proc. R. Soc. Lond. 385, 461-475. 
Mohri, N., Fukuzawa, Y., Tani, T., Saito, N., Furutani, K., 1996. Assisting electrode method for machining insulating ceramics. CIRP Ann. Manuf. Technol. 45 (1), 201-204.

Ng, S.H., Hull, J.B., Henshall, J.L., 2006. Machining of novel alumina/cyanoacrylate green ceramic compacts. J. Mat. Proc. Technol. 175, 299-305.

Pereira, O., Martín-Alfonso, J.E., Rodríguez, A., Calleja, A., Fernandez-Valdivielso, A Lopez de Lacalle, L.N., 2017. Sustainability analysis of lubricant oils for minimum quantity lubrication based on their tribo-rheological performance. J. Clean. Prod. 164, 1419-1429.

Richerson, D.W., 1992. Modern Ceramic Engineering: Properties, Processing, and Use in Design, second ed. Marcel Dekker, USA.

Samant, A.N., Dahotre, N.B., 2009. Laser machining of structural ceramics - a review. J. Eur. Ceram. Soc. 29, 969-993.

Sánchez, J.A., Cabanes, I., López de Lacalle, L.N., Lamikiz, A., 2001. Development of optimum electrodischarge machining technology for advanced ceramics. Int. J. Adv. Manuf. Technol. 18, 897-905.

Shaw, M., 2005. Metal Cutting Principles, second ed. Oxford University Press, , New York.

Strakna, T.J., Jahanmir, S., Allor, R.L., Kumar, K.V., 1996. Influence of grinding direction on fracture strength of silicon nitride. J. Eng. Mat. Technol. 118, 335-342.

Su, B., Dhara, S., Wang, L., 2008. Green ceramic machining: a top-down approach fo the Rapid fabrication of complex-shaped ceramics. J. Eur. Ceram. Soc. 28,
2109-2115.

Swain, M.V., 1979. Microfracture about scratches in brittle solids. Proc. R. Soc. Lond. 366, 575-597.

Trafny, E.A., 2013. Microorganisms in metalworking fluids: current issues in research and management. Int. J. Occup. Med. Environ. Health 26 (1), 4-15.

Westerheide, R., Driisedau, K.A., Hollstein, T., Schwickert, T., Zipse, H., 1996. Advances in characterisation of machined green compacts. J. Eur. Ceram. Soc. 17, 467-472.

Wichmann, H., Stache, H., Schmidt, C. Winter, M., Bock, R. Herrmann, C. Bahadir, M., 2013. Ecological and economic evaluation of a novel glycerol based biocide-free metalworking fluid. J. Clean. Prod. 43, 12-19.

Wu, Chuan-Yu, Ruddy, O.M., Benthamb, A.C., Hancock, B.C., Best, S.M., Elliott, J.A. 2005. Modelling the Mechanical Behaviour of Pharmaceutical Powders during Compaction Powder Technology, 152, pp. 107-117.

Xu, H.H.K., Jahanmir, S., 1995. Microfracture and material removal in scratching of alumina. J. Mater. Sci. 30, 2235-2247.

Zhao, F., Ogaldez, J., Sutherland, J.W., 2012. Quantifying the water inventory of machining processes. CIRP Ann. Manuf. Technol. 61, 67-70.

Zhong, Z.W., 2003. Ductile or partial ductile mode machining of brittle materials. Int. J. Adv, Manuf. Technol, 21, 579-585.

Zipse, H., 1997. Finite-element simulation of the die pressing and sintering of a ceramic component. J. Eur. Ceram. Soc. 17, 1707-1713. 